\title{
AKTIVITAS LIGNINOLISIS DARI BASIDIOMYCETES YANG DAPAT DIPAKAI UNTUK BIODEGRADASI DIOKSIN
}

\section{Ligninolytic Activity of Basidiomycetes Applicable for Dioxin Biodegradation}

\author{
Nuki Bambang Nugroho \\ Balai Pengkajian Bioteknologi BPPT \\ Gedung 630 Kawasan PUSPIPTEK, Setu, Tangerang Selatan, Banten 15314 \\ E-mail: nuki.bambang@bppt.go.id
}

\begin{abstract}
Chemical compounds belonging to dioxin group are known to be highly toxic environmental pollutant. Polychlorinated dibenzo-p-dioxin and polychlorinated dibenzofuran are produced during organic materials burning process. Pentachlorophenol, a compound similar to dioxin, is widely used as wood preservative, fungicide, bacteriocide, herbicide, algicide and insecticide. Some white-rot fungi have potential to produce lignin degrading enzyme and degrade dioxin compounds. The diversity of white-rot fungi in Indonesia provides potential source for environmental pollutant-degrading microorganisms. In this study, basidiomycetes were isolated from fruiting body and rotted wood samples which were collected from seven provinces in Indonesia. Three hundred seventy basidiomycete isolates were screened for dioxin degrading activity using dye-decolorization method. The result indicated that sixty isolates had dioxin degrading activity, three of which showed significant activity.
\end{abstract}

Keywords: Ligninolytic, basidiomycetes, biodegradation, dioxin, fungus

\begin{abstract}
ABSTRAK
Senyawa-senyawa kimia dalam kelompok dioksin telah diketahui sebagai polutan lingkungan yang sangat beracun. Dibenzo-p-dioksin terpoliklorinasi dan dibenzofuran terpoliklorinasi dihasilkan selama proses pembakaran bahan-bahan organik. Pentaklorofenol, suatu senyawa mirip dioksin, banyak digunakan sebagai pengawet kayu, fungisida, bakterisida, herbisida, algisida dan insektisida. Beberapa jamur pelapuk putih memiliki potensi untuk menghasilkan enzim pengurai lignin dan mendegradasi senyawa-senyawa dioksin. Keanekaragaman jamur pelapuk putih di Indonesia yang tinggi merupakan sumber potensial mikroorganisme pengurai polutan lingkungan. Pada kajian ini, basidiomisetes diisolasi dari sampel-sampel tubuh buah dan kayu lapuk yang diambil dari tujuh provinsi di Indonesia. Tiga ratus tujuh puluh isolat basidiomisetes telah diseleksi aktivitasnya sebagai pendegradasi dioksin. Metode dye-decolorization digunakan pada seleksi ini. Hasil seleksi menunjukkan bahwa enam puluh isolat basidiomisetes memiliki aktivitas sebagai pendegradasi dioksin, tiga isolat di antaranya menunjukkan aktivitas tertinggi.
\end{abstract}

Kata kunci: Ligninolisis, basidiomisetes, biodegradasi, dioksin, jamur 


\section{PENDAHULUAN}

Jaringan kayu terdiri atas tiga biopolimer utama; selulosa, hemiselulosa dan lignin. Lignin merupakan polimer aromatik sangat tidak beraturan yang disintesis pada tanaman oleh reaksi polimerisasi $p$ hidroksisinamil alkohol tersubstitusi. Reaksi polimerisasi ini dikatalisis oleh enzim peroksidase. Beberapa mikroorganisme, khususnya jamur pelapuk putih, dapat mendegradasi polimer lignin yang kompleks. Phanerochaete chrysosporium merupakan jamur pelapuk putih yang sering dipakai pada penelitian biodegradasi lignin (ligninolisis). Ligninolisis hanya terjadi jika ada substrat lain yang dapat didegradasi (Field et al. 1993). Setelah pertumbuhan awal $P$. chrysosporium berhenti karena keterbatasan karbon, nitrogen atau belerang, ligninolisis mulai terjadi.

Ligninolisis merupakan proses tidak spesifik. Senyawa yang memiliki struktur aromatik (seperti senyawa xenobiotic) sangat mudah didegradasi oleh enzim ligninolisis. Senyawa-senyawa kimia dalam kelompok dioksin telah diketahui sebagai polutan lingkungan yang sangat beracun. Dibenzo- $p$ dioksin terpoliklorinasi (polychlorinated dibenzo-p-dioxin / PCDD) dan dibenzofuran terpoliklorinasi (polychlorinated dibenzofuran I PCDF) dihasilkan pada proses pembakaran bahan-bahan organik (Valli et al. 1992; Wittich 1998). Pentaklorofenol (pentachloro-phenol / PCP), suatu senyawa mirip dioksin, banyak digunakan sebagai pengawet kayu, fungisida, bakterisida, herbisida, algisida dan insektisida. Banyak senyawa xenobiotic, seperti PCDD, $\mathrm{PCDF}$, polycyclic aromatic hydrocarbon (PAH), fenol terklorinasi, polychlorinated biphenyl (PCB), pestisida dan senyawa-senyawa pewarna, dapat dioksidasi pada kultur jamur pelapuk putih (Kamei dan Kondo 2005; Mori dan Kondo 2002a, 2002b, 2002c, Field dan Sierra-Alvarez 2008). Jamur dapat mendegradasi PCDD/PCDF pada kondisi aerob. Jamur menggunakan enzim (lignin peroksidase atau mangan peroksidase) untuk mengoksidasi molekul dari senyawa PCDD / PCDF (Urbaniak 2013). Selain jamur, bakteri yang diisolasi dari tanah terkontaminasi dioksin dapat mendegradasi fenol, dan hal ini menunjukkan juga kemampuan mendegradasi PCDD/PCDF (Bui et al. 2012). Beberapa enzim terlibat pada ligninolisis terutama lignin peroksidase (LiP) dan mangaan peroksidase (MnP). Beberapa jamur pelapuk putih (white-rot fungi) diketahui menghasilkan enzim LiP, salah satu enzim pengurai lignin (Buckley et al. 1998). Enzim LiP yang dimurnikan dapat mengoksidasi beberapa senyawa PAH menjadi PAH kinon, PCP menjadi tetrakloro- $p$-benzokinon, dan memecah diklorodibenzo- $p$-dioksin (dichlorodibenzo-p-dioxin / DCDD). Proses penguraian dioksin tidak hanya dilakukan oleh LiP, tetapi juga dibantu oleh MnP dan laccase (Lac). Beberapa jamur pelapuk putih, tetapi bukan P. Chrysosporium, juga menghasilkan enzim Lac. Enzim ini merupakan enzim yang bekerja pada o-kinol, p-kinol dan amino fenol. Lac berperan pada polimerisasi fenol dan oksidasi senyawa aromatik bukan fenol. Enzim dehalogenase dapat mendegradasi PCDD yang memiliki lebih dari empat subtituen klorin (Sakaki dan Munetsuna 2010).

Metode seleksi enzim oksidase, khususnya Lac dan peroksidase, biasanya berdasarkan reaksi pembentukan atau penghilangan warna sehingga pendeteksiannya mudah dilakukan. Penghilangan warna pada senyawa pewarna merupakan indikator terjadinya oksidasi awal senyawa-senyawa xenobiotic dan lignin (Pasti dan Crawford 1991). Jamur pelapuk putih dapat mendegradasi senyawasenyawa dioksin karena struktur kimia dioksin mirip dengan sebagian struktur lignin. Enzim peroksidase dihasilkan oleh jamur pelapuk putih mengkatalisis oksidasi lignin dan senyawa aromatik menyerupai lignin. Senyawa pewarna seperti Remazol Brilliant Blue R, Poly B-411, Poly R-478, Poly R-481, Poly S-119, Poly T-128 dan Poly Y-606 dapat mengalami penghilangan warna oleh jamur pendegradasi lignin (Glenn dan Gold 1983; Platt et al. 1985; Pasti dan Crawford 1991; Ollikka et al. 1993).

\section{BAHAN DAN METODE}

\section{Sampel}

Sampel kayu lapuk dan tubuh buah basidiomisetes diambil dari 7 provinsi di Indonesia, yaitu Sumatera Barat, Jawa Barat, Kalimantan Timur, Sulawesi Selatan, Sulawesi Utara, Bali dan Lombok. Sampel untuk isolasi basidiomisetes adalah kayu lapuk dan tubuh buah basidiomisetes. 
Seleksi Basidiomisetes sebagai pengurai dioksin dilakukan dengan metode dye decolorization. Basidiomisetes yang menunjukkan aktivitas pengurai dioksin selanjutnya diisolasi dengan metode single mycelium transfer.

\section{Metode seleksi}

Metode seleksi awal (primary screening method) mengadopsi metode dye decolorization sebagaimana diuraikan oleh Sato et al. (2002). Senyawa pewarna Remazol brilliant blue R (RBBR) mengalami pengurangan / penghilangan warna oleh jamur pendegradasi lignin, sehingga penghilangan warna ini merupakan indikator yang baik untuk mengetahui oksidasi awal senyawa xenobiotic dan lignin (Pasti dan Crawford 1991). Seleksi awal dilakukan dengan menginokulasikan sampel langsung ke permukaan media pewarna yang terdiri atas dua lapis. Lapis atas: $0,5 \%$ malt extract (Difco Laboratories, detroit, MI, USA), 1\% agar dan 1\% RBBR. Lapis bawah: Czapek Dox agar (Difco Laboratories, detroit, MI, USA). Benomyl $20 \mathrm{mg} / \mathrm{L}$ (Aldrich Chemical Co. Inc., Milwaukee, WI, USA) ditambahkan ke lapis atas media untuk menghambat pertumbuhan jamur-jamur yang tidak diinginkan.

Isolat yang terseleksi dengan dye decolorization diseleksi lanjut mengikuti secondary screening method (Gambar 1) (Sato et al. 2002). Setiap isolat yang terseleksi dengan dye decolorization ditransfer ke dalam empat labu Erlenmeyer $50 \mathrm{~mL}$ bertutup gelas berisi $5 \mathrm{~mL}$ medium rendah nitrogen (Tien dan Kirk 1988), dan dipreinkubasi pada $25^{\circ} \mathrm{C}$ selama 10 hari. Setelah preinkubasi, $20 \mu \mathrm{l}$ 2,7-DCDD (AccuStandard Inc., New Haven, CT, USA. dilarutkan dalam $\mathrm{N}, \mathrm{N}$-dimethylformamide / DMF) ditambahkan ke dalam dua labu sampai konsentrasi akhir 2,7-DCDD $10 \mu \mathrm{M}$ (kultur inkubasi 15 hari: A). Tutup labu Erlenmeyer dilapis rekat dengan pita Teflon setelah penambahan 2,7-DCDD. Selama 15 hari inkubasi pada $25^{\circ} \mathrm{C}, 250 \mu$ larutan glukosa $20 \%$ (konsentrasi akhir 1\%) ditambahkan dua kali dan oksigen ditambahkan empat kali ke dalam kultur (Gambar 1). Dua puluh mikroliter DMF (tanpa 2,7-DCDD) ditambahkan ke dalam dua labu lainnya (kultur kontrol: B), kemudian diperlakukan (inkubasi, penambahan glukosa dan penambahan oksigen) seperti kultur A. Satu hari sebelum akhir masa inkubasi, 2,7DCDD ditambahkan ke dalam kultur B, DMF ditambahkan ke dalam kultur A. Setelah inkubasi selesai, dilakukan perbandingan jumlah 2,7-DCDD tersisa dalam kultur A dan B.

Untuk mengambil 2,7-DCDD yang tersisa dalam kultur, dilakukan mengikuti Sato et al. (2002). Asam sulfat pekat sebanyak $5 \mathrm{~mL}$ ditambahkan sebelum ekstraksi dengan $n$-heksana (tiga bagian masing-masing $10 \mathrm{~mL}$ ) (Takada et al. 1996). Fraksi $n$-heksana dikumpulkan dan dicuci dengan aquades. Fraksi dikeringkan dalam desikator dengan penyerap air natrium sulfat kemudian dipekatkan sampai $0,1 \mathrm{~mL}$. Konsentrasi 2,7-DCDD ditentukan dengan GC-MS mengikuti kondisi yang dijelaskan oleh Sato et al. (2002). Antrasena digunakan sebagai internal standar.

\section{HASIL DAN PEMBAHASAN}

Dari isolasi ini diperoleh 370 isolat basidiomisetes, 60 di antaranya menunjukkan aktivitas penghilangan warna senyawa RBBR (Tabel 1). Perbandingan jumlah isolat aktif penghilang warna RBBR terhadap total isolat pada setiap lokasi sampel berkisar dari 6\% sampai $38 \%$. Isolat-isolat aktif penghilang warna RBBR diseleksi lebih lanjut menggunakan secondary screening method.

Persentase 2,7-DCDD yang tersisa dalam kultur $A$ dan $B$ ditunjukkan pada Tabel 2 dan Gambar 2. Dari 60 isolat yang diseleksi menggunakan secondary screening method diperoleh 12 isolat dengan kemampuan degradasi dioksin. Sebagian besar isolat ini menunjukkan laju recovery 2,7-DCDD yang mirip untuk kedua perlakuan

Tabel 1. Aktivitas penghilangan warna RBBR oleh isolat basidiomisetes

\begin{tabular}{lccc}
\hline \multirow{2}{*}{$\begin{array}{l}\text { Lokasi peng-ambilan } \\
\text { sampel }\end{array}$} & \multicolumn{3}{c}{ Jumlah isolat basidiomisetes } \\
\cline { 2 - 4 } & $\begin{array}{c}\text { isolat } \\
\text { dikoleksi }\end{array}$ & $\begin{array}{c}\text { isolat } \\
\text { aktif }\end{array}$ & $\begin{array}{c}\text { persentase } \\
\text { isolat aktif }\end{array}$ \\
\hline Sumatera Barat & 62 & 15 & $24 \%$ \\
Jawa Barat & 34 & 2 & $6 \%$ \\
Kalimantan Timur & 71 & 6 & $8 \%$ \\
Sulawesi Selatan & 105 & 11 & $10 \%$ \\
Sulawesi Utara & 39 & 11 & $28 \%$ \\
Bali & 26 & 10 & $38 \%$ \\
Lombok & 33 & 5 & $15 \%$ \\
\hline \multicolumn{1}{c}{ Total } & 370 & 60 & $16 \%$ \\
\hline
\end{tabular}


(A dan B). Hal ini menunjukkan bahwa sebagian besar isolat hanya memiliki kemampuan kecil dalam mendegradasi dioksin, kecuali isolat KT-BS, KT-BB dan SS-MN. Isolat KT-BS dan KT-BB diisolasi dari sampel asal Bukit Suharto dan Bukit Bangkirai Kalimantan Timur, sedangkan isolat SS-MN berasal dari sampel Malino Sulawesi Selatan. Perbedaan recovery 2,7-DCDD ditunjukkan isolat KT-BS (23\%), KT-BB (27\%) dan SS-MN (18\%). Perbedaan recovery 2,7-DCDD oleh ketiga isolat ini menunjukkan kemampuan degradasi dioksin yang nyata. Kemampuan ketiga isolat pendegradasi dioksin ini lebih besar dibandingkan galur pendegradasi dioksin, Phanerochaete sordida YK-624 (5\%) (Sato et al. 2002).
Tabel 2. Recovery 2,7-DCDD dari kultur inkubasi 15 hari dan 1 hari (kontrol)

\begin{tabular}{lccc}
\hline \multirow{3}{*}{ Isolat } & \multicolumn{3}{c}{ Recovery 2,7-DCDD } \\
\cline { 2 - 4 } & $\begin{array}{c}\text { inkubasi } \\
15 \text { hari (A) }\end{array}$ & $\begin{array}{c}\text { inkubasi 1 hari } \\
\text { = kontrol (B) }\end{array}$ & $\begin{array}{c}\text { perbedaan } \\
(\mathrm{B}-\mathrm{A})\end{array}$ \\
\hline SB-7 & $100 \%$ & $98 \%$ & $-2 \%$ \\
SB-13 & $88 \%$ & $92 \%$ & $3 \%$ \\
JB-17 & $78 \%$ & $79 \%$ & $2 \%$ \\
KT-BS & $76 \%$ & $99 \%$ & $23 \%$ \\
KT-BB2 & $64 \%$ & $91 \%$ & $27 \%$ \\
SS-MN & $82 \%$ & $100 \%$ & $18 \%$ \\
SU-12 & $75 \%$ & $76 \%$ & $1 \%$ \\
SU25 & $67 \%$ & $73 \%$ & $6 \%$ \\
BL-11 & $71 \%$ & $69 \%$ & $-2 \%$ \\
BL-18 & $56 \%$ & $66 \%$ & $10 \%$ \\
LB-18 & $39 \%$ & $39 \%$ & $0 \%$ \\
LB-24 $^{\text {Y }}$ & $38 \%$ & $30 \%$ & $-8 \%$ \\
YK-624 & & & $5 \%$ \\
\hline
\end{tabular}

*data dari Sato et al. (2002)

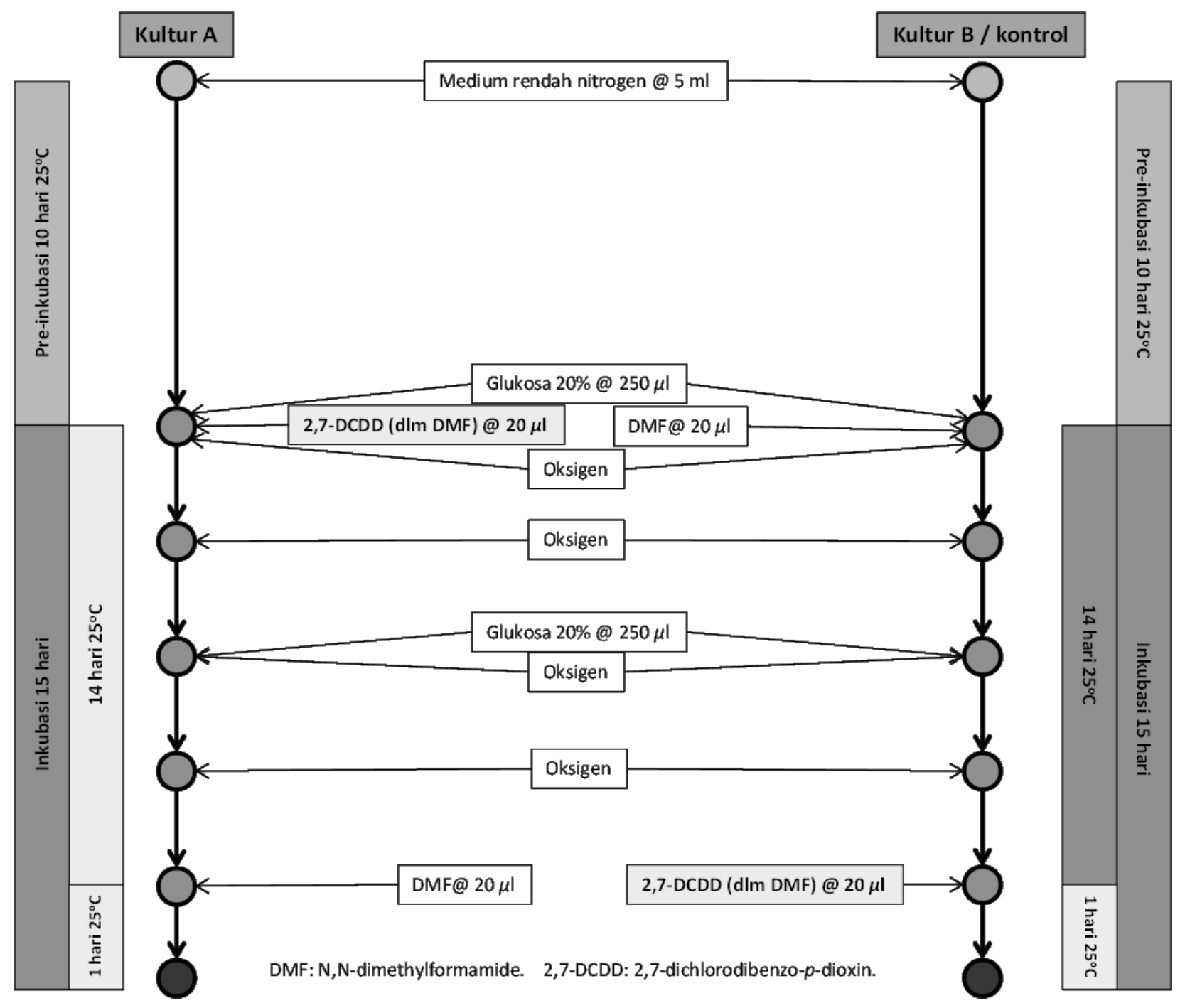

Gambar 1. Seleksi lanjutan (secondary screening method) 


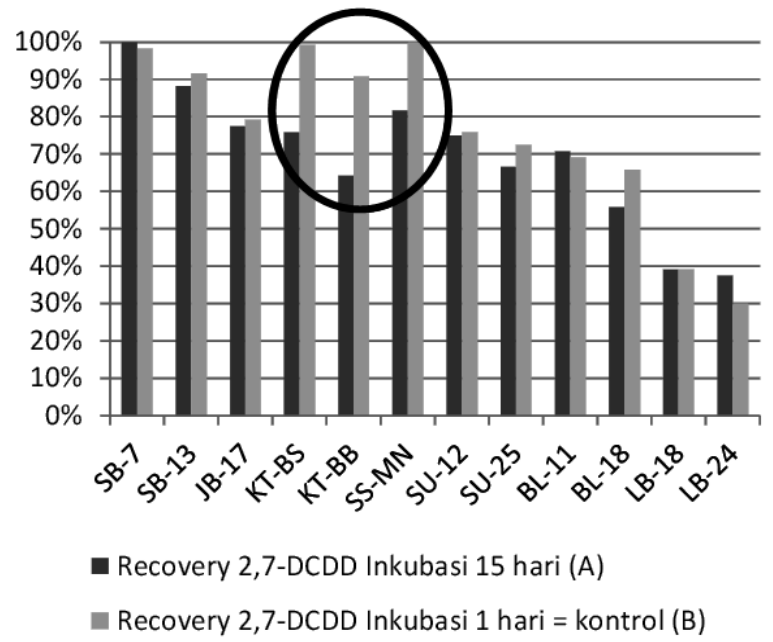

Gambar 2. Recovery 2,7-DCDD dari kultur inkubasi 15 hari dan 1 hari (kontrol)

\section{KESIMPULAN}

Metode dye-decolorization dapat digunakan pada seleksi basidiomisetes pendegradasi dioksin. Seleksi dengan metode dye-decolorization menunjukkan 60 isolat basidiomisetes yang menunjukkan aktivitas sebagai pendegradasi dioksin. Seleksi lanjutan dengan metode perbandingan degradasi dioksin pada kultur lima belas hari dengan kontrol menunjukkan ada 3 isolat yang menunjukkan aktivitas degradasi dioksin yang nyata.

\section{DAFTAR PUSTAKA}

Buckley KF, Dobson DW (1998) Extracellular ligninolytic enzyme production and polymeric dye decolorization in immobilized cultures of Chrysosporium lignorum CL1. Biotechnol Lett 20:301-306

Bui HB, Nguyen LT, Dang LD (2012) Biodegradation of Phenol by Native Bacteria Isolated From Dioxin Contaminated Soils. J Bioremed Biodeg 3:1-6. doi:10.4172/21556199.1000168

Field JA, de Jong E, Feijoo-Costa G, de Bont JA (1993) Screening for ligninolytic fungi applicable to the biodegradation of xenobiotics. Trends Biotechnol 11:44-49

Field JA, Sierra-Alvarez R (2008) Microbial transformation and degradation of polychlorinated biphenyls. Environ Pollut 155:1-12

Glenn JK, Gold MH (1983) Decolorization of several polymeric dyes by the lignindegrading basidiomycete Phanerochaete chrysosporium. Appl Environ Microbiol 45:1741-1747

Ollikka P, Alhonmäki K, Leppänen V, Glumoff T, Raijola T, Suominen I (1993) Decolorization of azo, triphenyl methane, heterocyclic, and polymeric dyes by lignin peroxidase isoenzymes from Phanerochaete chrysosporium. Appl Environ Microbiol 59:4010-4016

Kamei I, Kondo R (2005) Biotransformation of dichloro-, trichloro-, and tetrachlorodibenzo-p-dioxin by the white-rot fungus Phlebia lindtneri. Appl Microbiol Biotechnol 68:560-566

Mori T, Kondo R (2002a) Degradation of 2,7dichlorodibenzo-p-dioxin by woodrotting fungi, screened by dioxin degrading ability. FEMS Microbiol Lett 213:127-131

Mori T, Kondo R (2002b) Oxidation of chlorinated dibenzo-p-dioxin and dibenzofuran by white-rot fungus, Phlebia lindtneri. FEMS Microbiol Lett 216:223-227

Mori T, Kondo R (2002c) Oxidation of dibenzo- p-dioxin, dibenzofuran, biphenyl, and diphenyl ether by the white-rot fungus Phlebia lindtneri. Appl Microbiol Biotechnol 60:200-205

Pasti MB, Crawford DL (1991) Relationships between the abilities of streptomycetes to decolorize three anthron-type dyes and to degrade lignocellulose. Can J Microbiol 37:902-907

Platt MW, Hadar Y, Chet I (1985) The decolorization of the polymeric dye Poly-Blue (polyvinalamine sulfonateanthroquinone) by lignin degrading fungi. Appl Microbiol Biotechnol 21:394-396

Sakaki T, Munetsuna E (2010) Enzyme systems for biodegradation of polychlorinated dibenzo-p-dioxins. Appl Microbiol Biotechnol 88:23-30

Sato A, Watanabe T, Watanabe Y, Harazono K, Fukatsu T (2002) Screening for basidiomycetous fungi capable of degrading 2,7-dichlorodibenzo-p-dioxin. FEMS Microbiol Lett 213:213-217

Takada S, Nakamura M, Matsueda T, Kondo R, Sakai K (1996) Degradation of polychlorinated dibenzo-p-dioxins and polychlorinated dibenzofurans by the 
white rot fungus Phanerochaete sordida YK-624. Appl Environ Microbiol 62:4323-4328

Tien M, Kirk TK (1988) Lignin peroxidase of Phanerochaete chrysosporium YK-624. Methods Enzymol 161:238-249

Urbaniak M (2013) Biodegradation of PCDDs/PCDFs and PCBs. Di dalam: $R$ Chamy and F Rosenkranz (Ed.) (2013) Biodegradation-Engineering and
Technology, Intech Publisher.

Valli K, Wariishi H, Gold MH (1992) Degradation of 2,7-dichlorodibenzo-pdioxin by the lignin-degrading basidiomycete Phanerochaete chrysosporium. J Bacteriol 174:21312137

Wittich RM (1998) Degradation of dioxin-like compounds by microorganisms. App Microbiol Biotechnol 49:489-499 